\title{
Nutritional, Phytochemical and Antioxidant Analysis of Bee Bread from Different Regions of Malaysia
}

\author{
Z. A. OTHMAN ${ }^{1}$, LIZA NOORDIN, WAN SYAHEEDAH WAN GHAZALI, NORSUHANA OMAR AND MAHANEEM \\ MOHAMED ${ }^{2 *}$
}

Department of Physiology, School of Medical Sciences, Universiti Sains Malaysia, 16150 Kubang Kerian, Kelantan, ${ }^{1}$ Faculty of Medicine, Universiti Sultan Zainal Abidin, 20400 Kuala Terengganu, Terengganu, ${ }^{2}$ Unit of Intergrative Medicine, School of Medical Sciences, Universiti Sains Malaysia, 16150 Kubang Kerian, Kelantan, Malaysia

Othman et al.: Nutritional, Phytochemical and Antioxidant Analysis of Bee Bread

\begin{abstract}
Bee bread samples of stingless bee (Heterotrigona itama) collected from Kelantan (east coast), Selangor (central) and Perak (northern) regions of Malaysia were subjected to nutritional analysis using standard hydrolysis and oxidation methods. Phytochemical screening was carried out on aqueous and ethanol extracts of bee bread. Total phenolic and flavonoid contents, free radical scavenging activity and ferric reducing activity of the extracts were also assessed. All samples had essential and non-essential amino acids, carbohydrates, proteins, fat, flavonoids, tannins, phenols, xanthoproteins, cardiac glycosides, terpenoids, saponins, resins, and antioxidant activities. Sample from Kelantan had the significantly highest content of alanine, glycine and isoleucine, while sample from Selangor had the highest content of carbohydrate, total energy and proline. Sample from Perak had the highest content of fat. Bee bread ethanol extract demonstrated significantly higher antioxidant properties compared to bee bread aqueous extract with the highest total phenolic and flavonoid contents in sample from Perak and the highest free radical scavenging activity in sample from Selangor. Bee bread from Malaysia has good nutritional and antioxidant properties, which might indicate its potential to be a dietary supplement. The differences in compositions and antioxidant activities among the samples might be related to the floral sources and geographical locations.
\end{abstract}

Key words: Bee bread, extract, nutrients, amino acids, antioxidant

The consumption of bee products recently has been in high demand due to its powerful nutritional value and therapeutic properties. Bee bread has been included as one of scientific interest among honeybee's products. Bee bread is formed by bees which tightly pack the pollen into the beehives and store in the empty cells. Together with this, the bees collect the flower nectar and mix with its glandular secretion into the cells. About three quarter of the cell volume filled with the mixture and the remaining space is sealed with honey preparing for anaerobic environment inside. At this time, lactic acid fermentation takes place, subsequently providing bee bread rich in enzymatically-activated components ${ }^{[1,2]}$.

Oxidative stress generates dangerous free radicals, which affect human health and exposing them to disease by altering the naturally structured cellular lining of human body subsequently causing lipid peroxidation and effects on enzyme activity as well as producing carcinogenesis. Antioxidants benefit human

*Address for correspondence E-mail: mahaneem@usm.my

September-October 2019 body by neutralizing and removing free radicals in the blood stream. Surprisingly, bee bread has been reported to possess antioxidant ${ }^{[3]}$, antibacterial ${ }^{[4]}$, anticancer ${ }^{[5]}$ as well as hepatoprotective ${ }^{[6]}$ properties. The presence of antioxidant properties in bee bread has been reported worldwide especially in Europe countries. Bee bread is regarded as a well-balance diet as it consisted carbohydrates, fat, proteins ${ }^{[7]}$, fatty $\operatorname{acids}^{[8]}$, and trace minerals ${ }^{[9]}$ necessary for human health.

Composition of bee breads from various regions such as Lithuania ${ }^{[10]}$, Araucania ${ }^{[11]}$, Poland ${ }^{[7]}$, Ukraine ${ }^{[1]}$, Romania $^{[9]}$ and Georgia ${ }^{[3]}$ have been studied. Romanian bee bread has been shown to have antioxidant properties by 1-1-diphenyl-2-picrylhydrazyl (DPPH) method.

This is an open access article distributed under the terms of the Creative Commons Attribution-NonCommercial-ShareAlike 3.0 License, which allows others to remix, tweak, and build upon the work non-commercially, as long as the author is credited and the new creations are licensed under the identical terms

Accepted 03 July 2019

Revised 16 February 2019

Received 21 September 2018

Indian J Pharm Sci 2019;81(5):955-960 
Phenolic content of bee bread has been quantified in methanol and aqueous extracts using Folin-Ciocalteu (FC) method ${ }^{[11]}$. Meanwhile flavonoid content was demonstrated in Georgian bee bread using high performance liquid chromatography ${ }^{[3]}$. Compositions of bee bread varies depending on its botanical origin and season ${ }^{[12]}$. However, to date, no study has been reported on detailed properties of bee bread from Malaysia. Therefore, this study was carried out to evaluate and compare the nutritional, phytochemical and antioxidant properties of bee bread from different regions in Malaysia.

Bee breads samples from stingless bee (Heterotrigona itama) were purchased from three different regions in Malaysia including Kelantan (east coast), Selangor (central) and Perak (northern), during the period January-June 2016. These regions were selected based on the suggestion by Malaysian local beekeepers who recognized the geographical advantages of these 3 regions where the bee bread domestic production were most concentrated. All bee breads were freshly received and dried using a food dehydrator at $35^{\circ}$ until constant weight was achieved. Then each sample was ground to powder using a mini-blender and stored in a sterilized container at $-20^{\circ}$ until further analysis.

Analyses of carbohydrates, fats, and protein were carried out in accordance with in house method referred to Association of Official Analysis Chemists. Protein content was analysed using the Kjehdal method ${ }^{[13]}$, which involved heating of total nitrogen with sulphuric acid up to boiling point. The oxidation caused the nitrogen to be converted to ammonium sulphate and it was estimated by titration ${ }^{[14]}$. The fat was extracted from the sample via hydrolysis followed by evaporation and condensation using a Soxhlet apparatus ${ }^{[14]}$. The difference of weight before and after the process was calculated and expressed as a percentage. Total carbohydrate was measured by the difference from total sum of protein and fat in percentage ${ }^{[14]}$. Meanwhile, energy (kcal) was estimated by using the conversion factors where, energy $(\mathrm{kcal})=4(\%$ carbohydrate $)+4$ (\% protein $)+9$ (\% fat $)$.

Essential and non-essential amino acids were determined by Accq Tag Waters method ${ }^{[15]}$. It consisted of hydrolysis and heating process by using alphaaminobutyric acid as an internal standard. The actual weight for each amino acid was recorded after the injection vial by using limited volume inserts. All of the results were carried out in duplicate and reported as percentage and standard deviation.
Bee bread aqueous (BBA) extract and bee bread ethanol (BBE) extracts were prepared using distilled water and $70 \%$ ethanol, respectively. Briefly, $50 \mathrm{~g}$ of powdered bee bread was diluted in 10 volumes of distilled water or $70 \%$ ethanol and was kept in dark place at room temperature for $72 \mathrm{~h}$. After maceration, each solution was mixed with a magnetic stir at $500 \mathrm{rpm}$ for $10 \mathrm{~min}$ followed by centrifugation at $4000 \mathrm{rpm}$ for $10 \mathrm{~min}$. Supernatant was collected, filtered via Whatman paper No. 1 and freeze-dried $\left(5 \mathrm{mmHg}\right.$ pressure and $\left.-50^{\circ}\right)$. The yields obtained as BBA and BBE extracts were kept in $-20^{\circ}$ refrigerator for phytochemical screening and antioxidant analyses which were done within one week.

Phytochemical screening was performed using standard methods to detect the presence of alkaloids, flavonoids, glycosides, phenols, resins, saponins, tannins, terpenoids and xanthoproteins. Fifty milligrams of each extract was added to $2 \%$ hydrochloric acid $(\mathrm{HCl})$ and Mayer's reagent. Appearances of cream coloured precipitate indicated the presence of alkaloids ${ }^{[16]}$. Two hundred milligram of each extract was mixed with $1 \mathrm{ml}$ of distilled water or $70 \%$ ethanol and one drop of $10 \%(\mathrm{w} / \mathrm{v})$ ferric chloride was added to the mixture. Formation of a brownish precipitate revealed the presence of flavonoids ${ }^{[17]}$.

One hundred milligram of each extract was dissolved in $1 \mathrm{ml}$ of glacial acetic acid containing one drop of $10 \%(\mathrm{w} / \mathrm{v})$ ferric chloride. Glycosides were identified by adding $1 \mathrm{ml}$ of $98 \%(\mathrm{v} / \mathrm{v})$ sulphuric acid. Appearance of reddish brown-coloured ring at the interface of the mixture indicated for the presence of glycosides ${ }^{[18]}$. Fifty milligram of each extract was mixed with $5 \mathrm{ml}$ of distilled water or $70 \%$ ethanol. Appearance of intense purple colour indicated the presence of phenols ${ }^{[19]}$. Five hundred milligram of each extract was added with $5 \mathrm{ml}$ of distilled water or $70 \%$ ethanol. Appearance of turbidity indicated the presence of resins ${ }^{[18]}$. Five hundred milligram of each extract was shaken vigorously in $5 \mathrm{ml}$ of distilled water or $70 \%$ ethanol. The frothing solution was mixed with 3 drops of olive oil and then shaken. Appearance of persistent froth and emulsion upon mixing of frothing solution with oil indicated the presence of saponins ${ }^{[20]}$.

Five hundred milligram of each extract was mixed with $20 \mathrm{ml}$ of distilled water or $70 \%$ ethanol. The mixture was then added with $2 \mathrm{ml}$ of $0.1 \%(\mathrm{w} / \mathrm{v})$ ferric chloride. The appearance of olive green colour of mixture indicated the presence of tannins ${ }^{[21]}$. Five 
hundred milligram of each extract was added with $2 \mathrm{ml}$ of chloroform. Then, $3 \mathrm{ml}$ of $98 \%$ (v/v) sulphuric acid was carefully added to form a layer. Appearance of reddish brown colour indicated the presence of terpenoids ${ }^{[19]}$. Three drops of $15 \%(\mathrm{v} / \mathrm{v})$ nitric acid was added to $200 \mathrm{mg}$ of each extract in $1 \mathrm{ml}$ of distilled water or $70 \%$ ethanol. Appearance of yellow colour of the mixture indicated the presence of xanthoproteins ${ }^{[18]}$.

DPPH radical scavenging activity was evaluated using a previously reported method ${ }^{[22]}$ with slight modification. Presence of antioxidant turned the purple colour of DPPH into yellow. The assay mixture contained $1.5 \mathrm{ml}$ of DPPH radical solution $(0.09 \mathrm{mg} / \mathrm{ml}$ in methanol) and $0.75 \mathrm{ml}$ bee bread extracts. The absorbance of the remaining DPPH was determined after $15 \mathrm{~min}$ by spectrophotometer at $517 \mathrm{~nm}$. The measurement was performed in triplicate. Radical scavenging activity was calculated by the formula below, $\mathrm{I}=[(\mathrm{Ab}-\mathrm{Aa} / \mathrm{Ab})] \times 100$, where, $\mathrm{I}$ is \% DPPH inhibition, $\mathrm{Ab}$ is the absorption of a blank sample and Aa is the absorption of bee bread extracts solution.

The antioxidant activity of bee bread was determined using ferric reducing antioxidant power (FRAP) assay according to the method reported earlier ${ }^{[23]}$. Briefly, 1.5 $\mathrm{ml}$ of freshly prepared FRAP reagent was added to 200 $\mu 1$ of each bee bread extract. Subsequently, the mixture was incubated at $37^{\circ}$ for $4 \mathrm{~min}$ before the absorbance measured spectrophotometrically at $593 \mathrm{~nm}$ against a reagent blank. FRAP was prepared by mixing reagent of acetate buffer, 2,4,6-tris(2-pyridyl)-1,3,5-triazine solution in $\mathrm{HCl}$ and ferric chloride solution. Calibration curve of aqueous solution of ferrous sulphate heptahydrate was conducted with $\mathrm{R}^{2}: 0.9816$. The test was performed in triplicate for each bee bread sample and result was expressed as millimole of ferrous per litre bee bread ( $\left.\mathrm{mmolFe}^{2} / \mathrm{l}\right)$.

The content of total polyphenols was quantified according to the FC spectrophotometric method ${ }^{[24]}$ using gallic acid as a reference standard. One millilitre of FC reagent (1:10) was added to $200 \mu 1$ of bee bread extract and then was vortexed for $3 \mathrm{~min}$. After the addition of $1 \mathrm{ml}$ of $10 \%$ sodium carbonate solution, the extracts were incubated for $90 \mathrm{~min}$ at room temperature in a dark place. Standard curve was constructed using gallic acid ranging from $20-100 \mu \mathrm{g} / \mathrm{ml}$ with $\mathrm{R}^{2}=0.9819$. The test was carried out in triplicate and result was expressed as $\mathrm{mg}$ gallic acid equivalent/g bee bread (mgGAE/g).
Flavonoid contents were determined using aluminium chloride $\left(\mathrm{AICI}_{3}\right)$ reaction according to previous study $^{[25]}$. Briefly, $4 \mathrm{ml}$ of distilled water was added to $1 \mathrm{ml}$ of bee bread extracts. At zero time, $0.3 \mathrm{ml}$ of sodium nitrite $(5 \% \mathrm{w} / \mathrm{v})$ was added followed by $0.3 \mathrm{ml}$ of $\mathrm{AlCl}_{3}(10 \% \mathrm{w} / \mathrm{v})$ after $5 \mathrm{~min}$. Subsequently, $2 \mathrm{ml}$ of $1 \mathrm{M}$ sodium hydroxide solution was added after $6 \mathrm{~min}$. The mixture was shaken vigorously after which the volume was made up to $10 \mathrm{ml}$ of distilled water. Test was performed in triplicate by spectrophotometer at absorbance of $510 \mathrm{~nm}$. Calibration curve of quercetin was prepared as standard with $\mathrm{R}^{2}: 0.9741$. Results were expressed as $\mathrm{mg}$ of quercetin/g bee bread $(\mathrm{mgQE} / \mathrm{g})$.

All of the data were analysed using IBM SPSS version 22. Numerical data with normal distribution and homogenous variance were analysed using Oneway analysis of variance (ANOVA) followed by Tukey's post-hoc test for multiple comparison between all the three bee bread samples. Meanwhile, student t-test was used to compare the mean between ethanol and aqueous extract for each bee bread sample. The data were presented as mean (standard deviation) and a value of $p<0.05$ was defined as statistically significant.

To date, there are still not enough literature reporting the antioxidant activity and profile of bioactive compounds of bee bread specifically in Asian countries. Seventy percent of ethanol extract was used in this study as it is widely used due to its higher polarity compared to pure ethanol ${ }^{[26,27]}$ and it can produce higher extraction yield $^{[28]}$. This is the first study on nutrient analysis, amino acid content, and phytochemical screening of Malaysian bee bread.

Highest carbohydrate (59.55 \%), total protein $(18.37 \%)$ and total energy $(1478 \mathrm{~kJ})$ contents were found in bee bread from Selangor (Table 1). Bee bread from Poland has higher carbohydrate content $(71.9 \%)$ as the major component constituted by monosaccharides ${ }^{[7]}$. Present study showed that bee bread from Perak had the highest content of fat. Analysis of Lithuanian bee bread indicated the presence of saturated and unsaturated long chain fatty acids, including omega-3 linolenic acid (ALA $)^{[8]}$. All bee bread samples in the present study had both essential and non-essential amino acids (Table 2). Bee bread from Kelantan possessed significantly highest content of alanine, glycine and isoleucine. In other study, amino acids such as leucine, proline and valine were identified by gas chromatography-mass spectrometry method in small quantity in Romanian bee bread ${ }^{[7]}$. 
The phytochemical screening tests are helpful to determine the presence of bioactive components of an extract. Table 3 shows the results obtained from

\begin{tabular}{|c|c|c|c|}
\hline \multirow{2}{*}{$\begin{array}{l}\text { Nutrient } \\
\text { component } \\
\mathrm{g} / 100 \mathrm{~g}\end{array}$} & \multicolumn{3}{|c|}{ Bee Bread } \\
\hline & Kelantan & Selangor & Perak \\
\hline Carbohydrate & $58.73(0.66)$ & $59.55(0.34)$ & $32.74(1.74)^{a, b}$ \\
\hline Protein & $17.64(0.44)$ & $18.37(0.22)$ & $17.22(0.81)$ \\
\hline Fat & $2.17(0.13)$ & $4.51(0.71)^{\mathrm{a}}$ & $4.80(0.2)^{a, b}$ \\
\hline $\begin{array}{l}\text { Energy } \\
\text { Kcal/100g }\end{array}$ & $1365(0.0)$ & $1478(0.0)^{\mathrm{a}}$ & $\underset{a, b}{1020.5(17.68)}$ \\
\hline
\end{tabular}

Energy was calculated by summation of (fat $\times 9 \mathrm{kcal})+($ protein $\times 4$ $\mathrm{kcal})+($ carbohydrate $\times 4 \mathrm{kcal})$. ${ }^{\mathrm{a}} \mathrm{p}<0.05$ compared with Kelantan group, b $\mathrm{p}<0.05$ compared with Selangor group. One-way ANOVA followed by Tukey's post hoc test. All values are shown in mean (standard deviation)

\section{TABLE 2: AMINO ACID CONTENT OF DIFFERENT MALAYSIAN BEE BREADS}

\begin{tabular}{lccc}
\hline $\begin{array}{l}\text { Bee bread } \\
\text { g/100 g }\end{array}$ & Kelantan & Selangor & Perak \\
\hline Alanine & $0.91(0.00)$ & $0.86(0.01)^{\mathrm{a}}$ & $0.89(0.01)^{\mathrm{a}, \mathrm{b}}$ \\
Arginine & $0.90(0.02)$ & $0.77(0.12)$ & $0.74(0.00)$ \\
Aspartic acid & $1.50(0.01)$ & $1.47(0.12)$ & $1.45(0.01)$ \\
Glutamic acid & $2.10(0.01)$ & $2.08(0.20)$ & $2.00(0.02)$ \\
Glycine & $0.77(0.00)$ & $0.66(0.08)^{\mathrm{a}}$ & $0.68(0.01)^{\mathrm{a}}$ \\
Histidine & $0.49(0.00)$ & $0.35(0.09)$ & $0.37(0.00)$ \\
Hydroxyproline & $0.13(0.02)$ & $0.2(0.06)$ & $0.14(0.00)$ \\
Isoleucine & $0.74(0.02)$ & $0.65(0.02)^{\mathrm{a}}$ & $0.68(0.00)$ \\
Leucine & $1.20(0.00)$ & $1.06(0.87)$ & $1.14(0.01)$ \\
Lysine & $0.93(0.01)$ & $0.85(0.15)$ & $0.93(0.02)$ \\
Methionine & $0.39(0.00)$ & $0.31(0.06)$ & $0.34(0.00)$ \\
Phenylalanine & $0.77(0.01)$ & $0.67(0.21)$ & $0.65(0.00)$ \\
Proline & $0.83(0.02)$ & $1.56(0.26)^{\mathrm{a}}$ & $0.92(0.00)^{\mathrm{b}}$ \\
Serine & $0.81(0.01)$ & $0.74(0.05)$ & $0.74(0.00)$ \\
Threonine & $0.71(0.01)$ & $0.63(0.09)$ & $0.63(0.00)$ \\
Thyrosine & $0.48(0.01)$ & $0.42(0.14)$ & $0.35(0.00)$ \\
Valine & $0.84(0.00)$ & $0.78(0.03)$ & $0.81(0.00)$ \\
\hline
\end{tabular}

${ }^{a} \mathrm{p}<0.05$ compared with Kelantan group, ${ }^{\mathrm{b}} \mathrm{p}<0.05$ compared with Selangor group. One-way ANOVA followed by Tukey's post hoc test. All values are shown in mean (standard deviation)

TABLE 3: PHYTOCHEMICAL SCREENING

\begin{tabular}{|c|c|c|c|c|c|c|}
\hline \multirow{2}{*}{ Test } & \multicolumn{3}{|c|}{ BBA extract } & \multicolumn{3}{|c|}{ BBE extract } \\
\hline & Kelantan & Selangor & Perak & Kelantan & Selangor & Perak \\
\hline Alkaloids & - & - & - & + & + & +++ \\
\hline Flavonoids & ++ & ++ & + & ++ & +++ & + \\
\hline Glycosides & + & + & ++ & + & + & ++ \\
\hline Phenols & ++ & + & + & + & ++ & ++ \\
\hline Resins & ++ & ++ & + & ++ & ++ & + \\
\hline Saponins & ++ & ++ & + & ++ & +++ & + \\
\hline Tannins & + & ++ & + & + & + & + \\
\hline Terpenoids & ++ & + & + & ++ & + & +++ \\
\hline Xanthoproteins & + & ++ & + & ++ & + & + \\
\hline
\end{tabular}

BBA, bee bread aqueous; BBE, bee bread ethanol. A positive sign (+) indicates the presence of compound while double (++) and triple (+++) positive signs indicates the presence of compound with higher intensity of colour change 
TABLE 4: ANTIOXIDANT ANALYSIS OF MALAYSIAN BEE BREADS

\begin{tabular}{lccc}
\hline \multirow{2}{*}{$\begin{array}{l}\text { Antioxidant } \\
\text { test }\end{array}$} & \multicolumn{3}{c}{ Bee Bread } \\
\cline { 2 - 4 } & Kelantan & Selangor & Perak \\
\hline BPPH assay (\%) & & & \\
BBE & $8.95(0.32)$ & $3.24(0.22)^{\mathrm{a}}$ & $2.86(0.40)^{\mathrm{a}}$ \\
FRAP assay & $78.45(1.16)^{*}$ & $79.34(1.46)^{*}$ & $72.04(4.13)^{\mathrm{b}^{*}}$ \\
(mmol Fe $/ \mathrm{l})$ & & & \\
BBA & $0.94(0.03)$ & $1.00(0.00)^{\mathrm{a}}$ & $0.99(0.01)^{\mathrm{a}}$ \\
BBE & $1.07(0.02)$ & $1.08(0.01)$ & $1.08(0.01)$ \\
Total flavonoid & & & \\
content & & & \\
(mg QE/g) & $3.92(0.09)$ & $2.88(0.28)^{\mathrm{a}}$ & $3.77(0.09)^{\mathrm{b}}$ \\
BBA & $16.71(0.57)^{*}$ & $16.48(0.31)^{*}$ & $26.57(0.83)$ \\
BBE & & & $\mathrm{a}, \mathrm{b}^{*}$ \\
Total phenolic & & & \\
content & & & $14.35(0.23)^{\mathrm{b}}$ \\
(mg GAE/g) & $14.19(0.18)$ & $15.38(0.37)^{\mathrm{a}}$ & $22.54(0.11)$ \\
BBA & $21.32(0.16)^{*}$ & $21.96(0.26)^{*}$ & $\mathrm{a}^{*}$ \\
BBE & & & \\
\hline
\end{tabular}

BBA, bee bread aqueous extract; BBE, bee bread ethanol extract. DPPH; 1-1-diphenyl-2-picrylhydrazyl; FRAP, ferric reducing antioxidant power. ${ }^{\mathrm{a}} \mathrm{p}<0.05$ compared with Kelantan group, ${ }^{\mathrm{b}} \mathrm{p}<0.05$ compared with Selangor group. One-way ANOVA followed by Tukey's post hoc test. ${ }^{*} \mathrm{P}<0.05$ compared BBA (Independent $t-$ test). All values are shown in mean (standard deviation)

Romanian (13.92 mg GAE/g) and Ukraine (12.36 mg $\mathrm{GAE} / \mathrm{g})^{[1]}$.

Similarly, total flavonoid content of BBE extracts in all regions was significantly higher than BBA extracts (Table 4). Our finding on total flavonoid content in Malaysian BBE extract was higher than Romanian extracts $(5.13 \mathrm{mg} \mathrm{QE} / \mathrm{g})^{[30]}$. Meanwhile, BBA extract from Selangor possessed significantly highest FRAP value, whereas, insignificant differences of FRAP values were found for BBE extracts.

Taken together, BBE extracts showed higher total phenolic and flavonoid contents as well as higher antioxidant activities from DPPH and FRAP assays compared to BBA extracts which is in line with previous study ${ }^{[29]}$. These differences have been suggested to be attributed to the types of solvent used for the extraction, time interval of maceration as well as solvent concentration ${ }^{[31]}$. Furthermore, different solvents may have different polarity which can solubilise different phytochemical compounds with different chemical and biological properties ${ }^{[26]}$. Furthermore, the different findings between all the three samples could be attributed to the different floral sources in the different regions which was further supported by a previous study ${ }^{[12]}$.

In conclusion, Malaysian bee bread has good nutritional and antioxidant properties, which might suggest its use as a dietary supplement. The differences of the compositions and antioxidant activities among the samples might be related to the stingless bee foraging activity on different floral sources in different geographical locations.

\section{Acknowledgement:}

This work is supported by Universiti Sains Malaysia Short Term Grant (304/PPSP/61313189).

\section{REFERENCES}

1. Ivanisova E, Kacaniova M, Francakova H, Petrova J, Hutkova $\mathrm{J}$, Brovarskyi V, et al. Bee bread - perspective source of bioactive compounds for future. Potravinarstvo 2015;9:59298.

2. Vasquez A, Olofsson TC. The lactic acid bacteria involved in the production of bee pollen and bee bread. J Apic Res 2009;48:189-95.

3. Tavdidishvili D, Khutsidze T, Pkhakadze M, Vanidze M, Kalandia A. Flavonoids in Georgian bee bread and bee pollen. J Chem Chem Eng 2014;8:676-81.

4. Eswaran VU, Bhargava HR. Chemical analysis and antimicrobial activity of Karnataka bee bread of Apis species. World Appl Sci J 2014;32:379-85.

5. Markiewicz-Zukowska R, Naliwajko SK, Bartosiuk E, Moskwa J, Isidorov V, Soroczyńska J, et al. Chemical composition and antioxidant activity of beebread, and its influence on the glioblastoma cell line (U87MG). J Apic Sci 2013;57:147-57.

6. Ceksteryte V, Balzekas J. The use of beebread - honey mixture in the treatment of liver diseases in alcohol-dependent patients. J Chem Technol 2012;2:62-6.

7. Isidorov VA, Isidorova AG, Sczczepaniak L. Gas chromatographic - mass spectrometric investigation of the chemical composition of beebread. Food Chem 2009;115:1056-63.

8. Ceksteryte V, Jansen E. Composition and content of fatty acids of various floral origin beebread collected in Lithuania and prepared for storage in different ways. Chem Technol 2012;2:57-61.

9. Stanciu OG, Marghitas LA, Dezmirean D. Macro- and oligo-mineral elements from honeybee-collected pollen and beebread harvested from Transylvania (Romania). Bull UASVM Anim Sci Biotechnol 2009;66:276-81.

10. Ceksteryte V, Kazlauskas S, Racys J. Composition of flavonoids in Lithuanian honey and beebread. Biologija 2006;2:28-33.

11. Duran XA, Mardones IQ, Gutierrez MM, Ulloa DM. Total polyphenols in bee bread (Apis mellifera L.) from hives the Araucania region. Idesia 2014;32:107-11.

12. Baltrusaityte V, Venskutonis PR, Ceksteryte V. Radical scavenging activity of different floral origin honey and beebread phenolic extracts. Food Chem 2007;101:502-14.

13. Bremner JM, Mulvaney CS. Nitrogen-Total. In: Page AL, editor. Methods of Soil Analysis. $2^{\text {nd }}$ ed. Madison, Wisconsin, United States: American Society of Agronomy; 1982. p. 595624.

14. Cunniff P, Association of Official Analytical Chemists. Official 
methods of analysis of AOAC International. Washington, DC, USA: Association of Official Analytical Chemists; 1995.

15. Boogers I, Plugge W, Stokkermans YQ, Duchateau ALL. Ultra-performance liquid chromatographic analysis of amino acids in protein hydrolysates using an automated pre-column derivatisation method. J Chromatogr A 2008;1189:406-09.

16. Parekh J, Chanda S. Antibacterial and phytochemical studies on twelve species of Indian medicinal plants. Afr J Biomed Res 2007;10:175-81.

17. Bhandary SK, Kumari S, Bhat VS, Sharmila KP, Bekal MP. Preliminary Phytochemical Screening of Various Extracts of Punica Granatum Peel, Whole Fruit and Seeds. J Health Sci 2012;2:34-8.

18. Ganesh S, Vennila JJ. Phytochemical analysis of Acanthus Ilicifolius and Avicennia officinalis by GC-MS. Res J Phytochem 2011;5:60-5.

19. Mir M, Sawhney S, Jassal M. Qualitative and quantitative analysis of phytochemicals. Wudpecker J Pharm Pharmocol 2013;2:1-5.

20. Kaur R, Kalia P, Kumar NR, Harjai K. Phytochemical analysis of different extracts of bee pollen. Int J Pharm Bio Res 2013;4:65-8.

21. Shabbir M, Khan MR, Saeed N. Assessment of phytochemicals, antioxidant, anti-lipid peroxidation and anti-hemolytic activity of extract and various fractions of Maytenus royleanus leaves. BMC Complement Altern Med 2013;13:1-13.

22. Aljadi AM, Kamaruddin MY. Evaluation of the phenolic contents and antioxidant capacities of two Malaysian floral honeys. Food Chem 2004;85:513-18.

23. Benzie IFF, Strain JJ. The ferric reducing ability of plasma (FRAP) as a Measure of "“Antioxidant Power"”: The FRAP
Assay. Anal Biochem 1996;76:70-6.

24. Singleton VL, Orthofer R, Lamuela-Raventos RM. Analysis of total phenols and other oxidation substrates and antioxidants by means of Folin-Ciocalteau reagents. In: Pyle AM, Christianson DW, editors. Methods in Enzymology. Cambridge, Massachusetts, United States: Academic Press; 1999. p. 152-78.

25. Zhishen J, Mengcheng T, Jianming W. The determination of flavonoid contents in mulberry and their scavenging effects on superoxide radicals. Food Chem 1999;64:555-59.

26. Tiwari P, Kumar B, Kaur M, Kaur G, Kaur H. Phytochemical screening and Extraction: A Review. Int Pharm Sci 2011;1:98106.

27. Kumar V, Bhandari U, Tripathi CD, Khanna G. Evaluation of antiobesity and cardioprotective effect of Gymnema sylvestre extract in murine model. Indian J Pharmacol 2012;44:607-13.

28. Usman UZ, Bakar ABA, Mohamed M. Phytochemical screening and comparison of antioxidant activity of water and ethanol extract propolis from Malaysia. Int J Pharm Pharm Sci 2016;8:413-15.

29. Oltica S, Marghitas LA, Dezmirean D. Examination of antioxidant capacity of beebread extract by different complementary assays. Bulletin USAMV-CN 2007;63:1-4.

30. Cocan O, Marghitas LA, Dezmirean D. Total polyphenols, flavonoids and radical scavenging activity of beepollen and bee bread collected from Transylvania area. Bull UASVM Anim Sci Biotechnol 2009;62:1-5.

31. Savickas A. Evaluation of total phenolic content and antioxidant activity of different Rosmarinus officinalis L . ethanolic extracts. Biologija 2013;59:39-44. 